\title{
The end of art as a capitalist Kapitalist bir söylem olarak discourse sanatın sonu
}

\section{Meysem Samsun $^{1}$}

\begin{abstract}
In the present paper, the claim, art or painting is going through its end, is evaluated as a capitalist discourse; and some related samples were analyzed in terms of how they were passivized and become dysfunctional by the capitalist system. French thinker Jean Baudrillard is the most effective and distinguished sample of the claim, the end of art. In this point, after evaluating Danto's ideas from the modern perspective, the claim of "end of art" will be discussed through Baudrillard's post-modern perspective. When Baudrillard directed his gaze onto the world of art, the situation he saw was not a very optimistic one. Modern art and postmodern art, in which the thinker is also included, is the production of the Western World. As a result, in this sense, the literature of art is merely valid for the modern art taking its roots from the Western World and this domain of thinking. According to Baudrillard, art has lost its own privilege and purpose; it is not made for development of culture, but for consumption of this culture; and instead of existing through its own content of meaning, it has been unconsciously spread over all segments of the society. As a result, the discussion of what is art and what is not has progressively become more ambiguous.
\end{abstract}

Keywords: Art, capitalist discourse, meta, Baudrillard.

(Extended English abstract is at the end of this document)

\section{Özet}

Bu çalş̧mada sanatın ya da resmin sonunun geldiği savı kapitalist bir söylem olarak değerlendirilmiş, sanatın kapitalist sistem tarafindan nasıl edilgen ve işlevsiz kilındığına ilişkin örneklendirmelerle işlenmiştir. Sanatın sonu sav'ının, bu örneklendirme ile, en etkili duayen ismi Fransız düşünür Jean Baudrillard'dır. Burada, modern anlamda Danto’nun görüşlerine yer verildikten sonra "sanatın sonu" sav1, postmodern anlamda, Baudrillard üzerinden tartışlacaktr. Baudrillard bakışını sanat dünyasina çevirdiğinde gördüğü manzara iç açıcı değildir. Burada bahsedilen çağdaş sanat, postmodern sanat, düşünürün de içinde bulunduğu Batı dünyasının üretimidir. Dolayısıyla, bu bağlamda literatür, sadece Batı dünyası ve bu düşünce dünyasından beslenen çağdaş sanat için geçerlidir. Baudrillard'a göre sanat artk sahip olduğu ayrıcalığı ve amacını yitirmiş, kültürü geliştirmek için değil, tüketilmek için yapılmış ve kendi anlam içeriği ile var olmak yerine toplumun tüm katmanlarına bilinçsizce yaydırılmış ve neyin sanat olup neyin sanat olmadığı tartışmaları iyice bulanıklaşmıştır.

Anahtar Kelimeler: Sanat, kapitalist söylem, meta, Baudrillard.

1 Ph.D., Cumhuriyet University, Faculty of Fine Arts, Department of Sculpture, Sivas, Turkey. msamsun@cumhuriyet.edu.tr 
Samsun, M. (2015). Kapitalist bir söylem olarak sanatın sonu. International Journal of Human Sciences, 12(2), 1239-1250. doi:10.14687/ijhs.v12i2.3427

\section{Giriş}

Sanatın sonu söylemi, birden bire söylenmiş veya bir dil sürçmesi olarak algılanamaz. Bu yeni bir söylem değildir ve bu söylemi hazırlayan, besleyen pek çok etmen vardır. Bunun yanı sıra, söylem bilinçli hazırlanmış, üzerinde çok düşünülmüş, iyi tasarlanmış ve zamanlaması çok iyi hesaplanmış kapitalist toplumsal üretim ilişkilerinin kendi sanatçısını yaratma mücadelesinin bir tavrı olarak karşımıza çıkmışır.

Postmodernizm, pek çok şeyin yanı sıra sanatın siyasi konumunun sonunu da ilan etti. Seksenli yıllarda kuramcılar düşüncelerini resmin ölümü teması üzerinde durmuş, resim sanatının tükenişe doğru sürüklendiğini, sanat ve sanat eserinin kendinden uzaklaşttğı için artık gerçek sanatın hissettirdiklerinin dışında olduğu iddiası üzerine temellendiriyorlardı.

Postmodern sanat anlayışı en son noktada, neyin sanat olup, neyin olmadığ1 konusunda ciddi bir tartışma içerisine girdi. Donald Kuspit, "Sanatın Sonu" adlı kitabında, bir problematik olarak, sanat ve sanat eserinin piyasa, moda, pazarlama, marka gibi kelimelerle birlikte anılmasını konu ediyordu. Estetiğin itibarını kaybettiğini öne süren Kuspit, tinsel değerlere inanan sanatçı tipinin yerine, pazarın taleplerine göbekten bağlı post sanatçı tipinin aldığına dikkat çekiyordu. Bu problematik uzun bir süre sanat teorisyenlerinin en temel tartışmalarından biri olmuştur ve sanatın sonunun gelip gelmediği tartısması sanatı ve sanatçıyı da, özkimliğin kaybolması noktasında tedirgin etmiştir.

Neyin sanat olup olmadığ1 tartışması devam ederken Athur Danto'nun tezi duyulmaya başlandı. Danto "sanatın sonu ve sonrası" üzerine yaptığı çalışmalarda sanatın sonunu ilan ederken, siyasi sanat ideolojilerinin ve tarihsel ilerlemeciliğin de sonunun geldiğini vurguluyordu. Danto,"sanatın ölümü" makalesinde ortaya nasıl bir sanat çıarsa çıksın, artık güven tazeleyici bir anlatıya sırtını dayayamayacağını, böyle bir anlatının içinde öykünün bir sonraki uygun aşamasının bulunmayacağının altını çiziyordu. Sanat'ın sonu'nun ardından gündeme gelen çalışması 'Sanatın sonundan sonra" da ise; sanat tarihi felsefesine, sanatla ilgili anlatıların yapısına, sanatın sonuna ve sanat eleştirisinin temellendiği noktalara eğiliyordu. Danto’ nun ısrarla altını çizdiği, artık sanat yapılmadığ1 veya eskisi kadar iyi yapılmadığı değil, Batı sanatı tarihinde bir dönemin kapandığı ve apayrı başka bir dönemin başladığıdır...(Giderer, 2003:26-32)

Danto bu görüşüyle, daha önce sanat tarihinde ideolojinin temsili takip ettiğini, şimdi ise her şeyin meşru olduğu tarih sonrası bir döneme girildiğine işaret ediyor. Ona göre, sanat üretiminde izlenilmesi gereken felsefi veya üsluba dair kısıtlamalar kalkmış, sanat tarihi anlatısı bitmiştir.

Sol çizgide durduğu bilinen eleştirmenin çağdaş sanatta, güzellik konusunda ele aldığ1 yazılarla sanatta güzellik konusunun gündeme gelmesini sağladı. Diğer bir yaklaşımı da sanat 
Samsun, M. (2015). Kapitalist bir söylem olarak sanatın sonu. International Journal of Human Sciences, 12(2), 1239-1250. doi:10.14687/ijhs.v12i2.3427

üretiminin farklılaşması üzerine oldu. ${ }^{2}$ Sanat ile sanat olmayanın sınırı ortadan kalkmıştır. Sanatı sanat olarak belirleyen ve sanatçı ile biricikliğe ulaşan empirik deneyim yerini kolektif bir anlayışa bırakarak 'piyasalaşmış'tır.

Çağdaş sanatta çeşitliliği olumlu karşılayan Danto bize şunu söylemeye çalışıyor: Çağdaş sanat artık olması gerektiği gibi büyük anlatılarla temsil edilmeye hiçbir şekilde izin vermiyor ve tarihin sınır çizgisi ile ilişkilendirilemez.

Düşüncemize göre, Danto’nun yukarıda kısaca değinilen "sanatın sonu” söylemi, gelişen kapitalist sistem sayesinde popüler bir söylem haline gelmiştir. Kapital sınırları ortadan kaldırmış, sanat para ile ‘sahip olunan’ ama 'sanat olmayan bir meta haline dönüşmüştür. Bu metalaştırmada ilk önce fotoğraf makinesinin icadı ile resmin öleceği iddia edildi. Kapitalist sistem 'sürekli öğüten bir değirmen gibi', yeni bir şeyler oluşurken sürekli olarak bir şeyleri öldürme, bir şeylerin sonunu getirme merağını da kapitalist sanatçıya yükledi. Oysa zamanla teknolojinin gelişmesi, insanın gelişmesine de olanak sağladı ve birbirini öldüreceği iddia edilen şeyler aksine birbirilerini geliştirip birbirilerine oldukça yararlılmuşlardır. Örneğin fotoğrafın resim sanatını öldürmek yerine ona daha geniş olanaklar sağlaması, dijital sanatın doğmasına zemin hazırladı. Sanat nesnelerinin fotoğraflanması bile fotoğrafin resim sanatına sağladığı çok ciddi bir katkı olarak sayılabilir.

\section{1. "RESMİN SONU" SÖYLEMİ}

Sanatın sonu ile resmin sonu iç içe geçmiş sorunlar olarak görülebilir. Sanatın sonundan söz edilmeden önce, resmin sonundan bahsedilmişti. Sanatın sonundan bahsedilirken genellikle resim sanatı ön plana çıkartlmıştır.

Resmin sonundan ilk söz eden zamanının ünlü ressamlarından olan Paul Delaroche'dur (1797-1859). Deguerreotype ${ }^{3}$ tekniğinin tanınmasında etkili olmuştur. 1839 Haziran'ında, Daguerre'nin icadı ile ilgili kurulacak bir komiteye Fransız hükümetince başkanlık etmesi istenmiştir. Çalışmalar sonunda hazırlanan raporda, Delaroche, "bu günden itibaren artık resim ölüdür" demiştir. Yine de fotoğrafin sanata sonsuz hizmetler vereceği inancındadır (Giderer, 2003: 59).

Delaroche zamanında fotoğraf, kabul görmeyen bir şeydir. Öyleki nufuzlu birinin onayına muhtaçtır. Bu anlamda Delaroche’nun onayı önemlidir çünkü kendisi ünlü bir ressamdır. Delaroche’nun resmin ölümünden sözetmesi, fotoğrafın tanınıp ve kabul görmesinde önemli bir rol oynamıştır.

\footnotetext{
2 Andy Warhol tarafından başlatılan bu farklılaşma konusuna Danto şu şekilde yaklaştı 'Warhol'un Brillo kutuları, görsel olarak brillo kutularından ayırt edilemiyorsa, bu sanatın görsel farklıllı̆ıyla tanımlanamaz olduğunu gösterir ve bu nedenle sanatın felsefi olarak karakterize edilmesi gerekir"

3 İlk fotoğraf imgesini görüntüleme sürecinde kullanılan bir tekniktir.İmge,bazı kimyasallara duyarlı olan gümüşle parlatılmış bakır bir levha üzerinde doğrudan pozitif olarak görülmektedir.Yöntem,Louis Jacques Mande daguerre tarafindan bulunmuş ve ilk olarak Nicephore Niepce tarafindan kullanılmıştır.
} 
Hakkı Engin Giderer fotoğraf ve resim ilişkisi için şunları söylüyor:

Fotoğraf, resmin ölümü sorunu ile ilgili konulardan yalnızca birisidir... şu gerçeği vurgulamakta yarar vardır: bu gün fotoğrafin da geleceği tartışma konusudur. Fotoğrafın ölümü de artık dile getirilmiştir ve tartışılmaktadır. Kaynak olarak da Nazif topçuoğlu' nun, fotoğraf ölmedi ama tuhaf kokuyor, adli eserini vermektedir (Yky, 2000: 113-23).

Sanatın sonu sorunundan söz edilirken resim sanatının ilk örnek olarak verilmesi, sanatlar içerisindeki statüsü nedeniyledir. Giderer' in tabiri ile, bir binanın çatısını sökmek demek onu kullanılmaz duruma getirmek demektir. En tepede, ekonomik açıdan en çok kazanç sağlayan, en tanınan ve talep edilen, en çok beğenilen ve çalışan parça ortadan kaldırıldığında, sanatın sonu da kolayca gelebilir.

Bu aşamada bazı sorular açıklanmak için ortada durmaktadır. Temel sorun resmin ve sanatın neden öldürülmek istendiğidir. İnsanlar sanattan ve resimden neden kurtulmak istesinler bununla elde edebilecekleri neler var? Ya da sanat, onu öldürmek ya da sonlandırmak isteyenlere ne gibi zararlar vermektedir? Sanatın sonu ve resmin sonu söylemleri bir eleştiriyi mi dile getirmektedir yoksa bu yalnızca bir geleceği görme çabası mıdır?

Bu sorulara verilecek en çarpıcı yanıt Dada örneğidir. Dada hareketi I.Dünya savaşına karşı bir tepkidir.(bu aynı zamanda kapitalizme de bir tepkidir) Modern çağa kuşku ile bakan aklın, savaşlara kurban edildiği bir dönemin başlangıcını yaşayan bu sanatçılar, o zamana dek kabul edilen tüm modern sanat formlanına hırsla saldırmışlar ve bu değerleri yıkmaya çalışışlardır. Genç Dadacılar çılgınlığı bir silah olarak kullanmışlar ve amaçlarının sanat yapmak değil modern düşünce ${ }^{4}$ ile sunulan sanatı rezil etmek olduğunu söylemişlerdir. Dada hareketi, kapitalist toplumun insanı yok eden, aşağılayan, aptal durumuna düşüren savaşları karşısında umutsuzluğa düşmüş, her şeyden şüphe duyan sanatçıların isyanıdır. (Giderer, 2003: 60-61)

Kurt Schwitters "sanatçının tükürdüğü her şey sanattır" diyordu. Bir yapıtı sanat yapan, biçimi, konusu, içeriği, türü ve yansıttı̆̆ ustalık değil sanatçının onun sanat olduğunu bilmesidir.(...) Aynı dönemde, öbür yapıtlarında Arp, insan elinden çıkma nesnelerin biçimlerini kullanmış, fakat bu dörtgene benzeyen biçimleri düzenlerken, sanki tasarladığı bir plana göre değil de, yer çekimi ve havanın hareketi gibi daha karmaşı güçlerin belirlemesine göre, başka bir değişle rastlantının yasalarına uymuş, böylece işin içine doğayı da katmıştır. Burada da sanatçı, Kübistlerin yapıştırma tekniğinden yararlanmakta, fakat sonucun gerçekliği yansıtıp yansıtmamasından çok, sanatçının yaratıcılık payının sanıldığı

\footnotetext{
${ }^{4}$ Modern kelimesi Latince modo'dan gelmekte ve 'yenileyin' anlamında kullanılmaktadır. Modern düşünce ile insana sunulan mutluluk reçeteleri insanlığı iki dünya savaşına götürmüş ve 55 milyon insanın ölümüne neden olmuştur. Bu bağlamda 'modern düşünce' ile bu düşüncenin insanlığa sundukları eleştiri süzgecine alınmıştır. İşte Dada'cıların modernizme isyanları bu perspektiften görülmelidir.
} 
kadar önemli olup olmadığ1 üzerinde durmaktadır. Bir sanat yapıtının ortaya çıkışında, yalnız geleneksel ustalıklardan değil, aynı zamanda denetleme işlevinden de vazgeçmesi Dadacıların özelliklerinden biriydi. (Lynton, 1982: 56).

\section{SANATIN KAPİTALİSTLEŞME SÜRECİ}

Kapitalist sistemin en belirgin yapı taşı metadır. Duhm metayı şöyle tanımlamaktadır:

"Meta, belli bir kullanım ve belli bir değişim değeri olan bir üründür. Kullanım değerinin ne olduğu meydandadır: Ekmek, yemek içindir, otomobil binmek ve kullanmak içindir vs... yani bir metanın kullanım değeri, onunla belli insani ihtiyaçların tatmin edilebilmesinde yatar. Metanın, toplumsal analiz açısından çok daha önemli olan niteliği, onun değişim değeridir. Değissim değeri, belli bir nicelik ilişkisi bildirir ve bu ilişki içinde, bir meta başka bir metaya ya da paraya karşıllk değiş tokuşa sokulur. Metalar, kullanım değerleri olarak değil de değişim değerleri olarak birbirileriyle ilgilidirler. Meta üretiminin tümü, değişim değeri üzerinden belirlenir. Metaların üretimi sırasında ağır basan soru, bu üretimle handi ihtiyaçların giderileceği değil, meta karşıllğında alacağımız bedelin ne kadar büyük olduğudur. Herhangi bir yolla satılabilecek ne varsa üretilmelidir ve her şey, her çiçek, her hediye, yerine getirilmesi söz konusu olan her istek satın alınabilir olmalıdır. Sadece meta olan bir şey kazanç açısından kullanilabilir olmaktadır.”(Duhm, 1996: 58-9)

$\mathrm{Bu}$ anlamda sanata ve sanat nesnesine bakıldığında metalaşma, sanatın özgürleşmesi için bir engeldir.” Nasıl daha çok kar elde edebilirim” diyen pazar içinde, özgür sanatçıya yer olmadığı gibi özgür sanat nesnesine de yer yoktur. Kar, sanatın amacı olduğunda, sanatçının duyarlı̆̆ı, araştırması, sanat yapma ve sanatını paylaşma süreci bundan etkilenmektedir. Oysa sanatın temel amacı, sanatçının kendisini, çevresini ve toplumsal sorunları özgürce anlatabilmesidir. En çok hangi konunun veya hangi stilin para kazandıracağı sorusunun ardından gitmek sanatı ucuzlaştırmakta hatta boğmaktadır.

Burgin'e göre, sanatın kapitalistleşme süreci şöyle bir seyir izlemiştir: Eski Yunan'da sanat, kurallar tarafindan yönetilen herhangi bir aktiviteye verilen bir isimdir. İçinde içtepi ya da sezgi olan bir aktivite değildir. Örneğin şiir ve müzik, sanatlar içinde üst sıralarda yer almamışlardır. Entelektüellik ve el hüneri ayrımı yoktur. Mantık ve ayakkabı yapımı yan yanadır. Ortaçağ'da sanatlarda ayrımlar oluşmaya başlamıştır. " Mekanik olan sanatlar" ve "liberal sanatlar" ilk ayrımı oluşturmuştur. Resim ve Heykel, liberal sanatlar içinde bir alt grubu oluşturmuştur. Rönesans'ın ilk yıllarında resim, liberal sanatların ilk sıralarına yükseltilmiştir. 17.yüzyılda sanatlarda, zanaat ve bilim ayrımı yapılmışır. 1747'de Abbe Charles Batteaux, yedi sanatı "güzel sanatlar" adı altında 
Samsun, M. (2015). Kapitalist bir söylem olarak sanatın sonu. International Journal of Human Sciences, 12(2), 1239-1250. doi:10.14687/ijhs.v12i2.3427

sınıflandırmıştır. 19. yüzyıl "görsel sanatlar" ayrımı oluşmuştur. Resim, heykel ve mimari bu sınıflandırma içinde yer almıslardır.

Burgin burada, resmin statüsünün başlangıçtan bu yana aynı olmadı̆̆ı, kapitalistleşme sürecinde kültürel ve teknik değissimlerle birlikte üstün bir statüye ulaştırıldığını anlatmak istiyor. Kapitalist kültürün içinde, resmin sanatlar hiyerarşisinde en üstte olması, bir anlamda kapitalist çıkarlarla ilişkilidir.

Canan Beykal, Sanat Ölüyor mu? (sana t-dunyamiz - sayz-76, bahar, 2014) adlı makalesinde şöyle demektedir: "sanatın ölüm ilanının verilmesi, sanat pazarının yaşadığı bir krizi işaret ediyorsa bunun sanatla ilişkisi olabilir mi? Sorusunu sormaktadır. Baudrillard'ın 'Sanatın Komplosu” adlı makalesine atıfta bulunarak, bu komplonun en müstehçen şeyinin para olduğunu söylemektedir. Ona göre paranın iktidarındaki bu gezegende, sanatçı sanatını 'sanat içi ve dışı dâhil' her şeyle ve sanatçı haricindeki herkesle paylaşmaktadır. Dadacılar, değerli dinlerini, inançlarını, düşünürlerini, idollerini ve sanatçlarını 'olması gereken sanat uğruna' hiçliğe defetmişlerdir. Bu günkü sanat ise dışkıyla oynamakta, iğrenme üzerine bir söylem geliştirmekte ve vandalizmi bir değer olarak hoş görmektedir. Yazar sanatın elinde hiçbir temiz alan kalmadığını işaret ederken; Dışkı ve Şiddet dâhil her şeyin metalaştırıldığı bir ortamda sanat da kendi payına düşeni almaktadır.”

Bir olgusal gerçeklik olarak sanat kendini bir nesne üzerinde ya da bir nesne aracıllğı̆la gerçekleştirir. $\mathrm{Bu}$ nesne; taşınabilir, sergilenebilir ve alınıp satılabilir. Durumun böyle olması kapitalizmi kendi içinde sanat eserinin taşınabilir, sergilenebilir ve alınıp satılabilir olması bağlamında masum kılmaz; kapitalizm sanatın içini, sanat eserinden hareketle boşaltmaktadır.

Kavramsal sanat, sanatın nesnel olarak varolması durumunu 'kapitalizmin metası' nedeniyle terk etmeye kalkışmışır. Kapitalizm ve sanat arasındaki bağı açık bir biçimde gösteren bir örnek olarak Haacke'nin çalışması verilebilir. Hans Haacke bir kavram sanatçısıdır. 1970 yılında, New York Modern Sanat Müzesi’ndeki “information” adlı sergide, müzeyi gezenleri oy vermeye davet eden bir etkinlik gerçekleștirir. Oy konusu, Rockefeller'dır. O dönem New York valisi olan Rockefeller, aynı zamanda büyük bir sanat koleksiyoncusudur. Müze üzerinde de söz sahibi olan vali, Vietnam savaşı sırasında da aktif bir rol oynamıştır. Dolayısıyla sanatın parası ve savaşın parası, sanatsal, sanatsal beğeni ve katillik, müze ve iktidar arasındaki ilişki sorgulanması gereken bir durum oluşturmuştur. Ve oylama "Rockfeller" refüze edilmeli mi sorusuna verilen gizli oyların çoğu "evet" olmuştur.

Sanatın metalaşması konusunda nevi şahsına münhasır bir örnek olarak Andy warhol verilebilir. Warhol, yüksek kültür ile kitle kültürü arasında bir uzlaşma sağlamaya çalışırken kapitalizmin fay hattında ilginç bir yöntem dener. "Fabrika" adını verdiği atölyesinde, yardımcılarıyla birlikte, çalışmalarının bir fabrikadaki gibi yapıldığını, el işi resmin onun resimlerinden çok uzak 
olduğunu söylemektedir. Ona göre mekanik olan, bugün demektir. Bundan dolayı, o,çok sayıda insan için çok sanat yapmaktadır, çünkü sanat herkes için olmalıdır. Warhol şöyle demektedir:

Ticaret sanatı (business art), sanattan sonraki adımdır. Ben ticari bir sanatçı olarak başladım ve ticari bir sanatçı olarak bitirmek istiyorum. Yaptığım şeye sanat dedim ya da her neyse, ona sanat dendi. Ben bir sanat tüccar1 ya da tüccar sanatçı olmak istedim. Ticarette iyi olmak sanatın en ilgi çeken türüdür (akt. Giderer, 2003: 106).

Popüler kültürün mitlerinin çok bilinen görüntülerini sürekli çoğaltarak mekanik çağın sıkıntısını, herkes için yapılan sanatın yüzeyselliğini, paranın en zavallı şeyleri bile değerli kılan gücüne örnek olarak Warhol en iyi örneklerden birisidir.

Sontag sanatın kendi içine kapanmasına, soyutlaşmasına, gülünç bir parodiye dönüşmesine ve süsleyici olmasına, metalaşmadan farklı olarak başka bir ölçüt getirir: Yorum. Ona göre yorumdan kaçma, modern resmin kendine özgü bir niteliği olmuştur. Soyut resim, sıradan anlamıyla içeriksiz olma çabasıdır; çünkü yorum yoksa içerik de olamaz. Pop sanat da aynı sonuca bunun tam tersi bir yoldan ulaşmıştır. Kullandığı içerik öylesine bağırır ve öylesine açıktır ki, yine yorumlanamaz olup çıkar. Sontag'ın 'yorum' dediği (interpretation) holistik görüşün metodudur. Anlama atkına dayanır. Yorum yapanın, yorum yaptı̆̆ alanın tüm tarihsel arka planını bilmesi gerekir. Sontag şunu söylemek istiyor: Kendisini modern olarak ortaya koyan -sözde resmin ve bunun sanatınınsanatçlarının resmin neliğinden haberi yoktur çünkü onların hiçbir tarihsel arka planı yoktur. $\mathrm{Bu}$ çerçevede yapılanlar olsa - olsa sanat adına 'soytarılıktır'.

Kısacası kapitalizm de her şey satıl1ktır. Her meta kendi grubuna ait bir pazarda satilmaktadır. Sanat yapıtı ya da sanat nesnesi de sanat pazarında satılmaktadır. Pazar, galerisiyle, müzesiyle, eleştirmeniyle sanatçı ve sanat üzerinde egemenlik kuran bir güçtür.

\section{BAUDRILLARD VE SANATIN SONU SÖYLEMİ}

Şimdiye kadar incelediğimiz düşünürlerin hiç birisi sanatın sonu konusunda Baudrillard kadar keskin fikirli değildir. Baudrillard bu gün modern sanatın artık olmadığını söylemektedir. Sözünü ettiği sanatı şöyle tanımlıyor:

Macera olarak sanat; yanılsama olarak sanat, gerçekliğe karş1 bir başka sahne kuran sanat, bir tualin üzerine konan çizgi ve renkler gibi, varlıkların anlamlarını yitirip kendi varlık nedenlerini aşarak bir baştan çıkma süreci içinde ideal biçimlerine ulaşabildikleri aşkın bir figür olarak sanattır (Baudrillard, 1995: 19).

Sanatın her yerde çoğaldığı görülmektedir. Sanat üzerine söylem daha da çoğalmaktadır, ancak sanatın ruhu yok olmuştur. Artık, ne temel kural, ne yargı ne de zevk ölçütü vardır. Bu gün 
Samsun, M. (2015). Kapitalist bir söylem olarak sanatın sonu. International Journal of Human Sciences, 12(2), 1239-1250. doi:10.14687/ijhs.v12i2.3427

sanat alanındaki hiçbir şey diğerine karşıt değildir. Yeni dışavurumculuk, Yeni figürasyon: tüm bunlar bir farksızlık içinde bir arada bulunmaktadır.

Baudrillard'a göre kavramsal sanat, minimal sanat, geçici sanat ve karşıt sanat tüm bu şeffaflaşma, yok olma ve cisimsizleşme estetiği içinde sanatın maddesizleștirilmesinden söz etmektedir. Yani nesnesiz bir sanat söz konusudur. Hatta daha ileri gidilerek sanat, çılgın bir reklamcılık alanı içine sokularak boğulmuş, simülasyon gerçek sanatın üstünü örtmüştür.

Baudrillard'ın felsefesi temelde simülasyon düşüncesine dayalıdır. Düşünür, simülasyonu şöyle açıllamaktadır:

Simülasyon, basit anlamda taklit yapmak değildir. Bir kimse hasta taklidi yapıyorsa, karşısındakini, yatağa yatarak inandırmaya çalısır. Eğer bir kimse simülasyon yaparsa kendisinde hastalı̆̆a ilişkin belirtiler üretir. Böylece taklit yapmak ya da başka türlü göstermek, bozulmamış gerçeklik ilkesinden ayrilır."Fark" her zaman belirgindir, ama maskelenmiştir. Simülasyon ise, doğru ile gerçek, gerçek ile düşler arasındaki farkı zorlar. Eğer simülasyon yapan hasta, hastalık belirtisini üretirse hasta mıdır? Değil midir? Bu durumda simülasyon, hastanın hasta olup olmadığına karar veremediği durumdur (Baudrillard, 1998:13).

Baudrillard bize Nietzsche'den getirerek şunu söylemek istiyor: Simülasyonda bir dekadent durum söz konusudur. Neden - sonuç birbirine karışmış, amaç ya da amaçlilıklar ortadan kalkmış, başıboşluğun egemen olduğu bir toplumsal yap1 hüküm sürmektedir. Yapılanlarda sorumluluk aranmaz ve bu olumsuz gidiş her zaman üstün tutulur. Gerçekten de kendisine 'modern' denilen günümüz sanatında bunları görmek mümkündür.

Baudrillard' in bu konudaki görüşlerini özetleyen Ryan şöyle demektedir:

Günümüz, simülakr çağıdır ve hiçbir yerde gerçeklikle temas etmeyen gösterenlerin ve temsillerin sonsuz dolaşımı söz konusudur. Dolayısıyla yanlış imge, en az herhangi bir varsayılan hakikat kadar doğrudur (Michael Ryan, "Postmodern Siyaset", modernite Versus postmodernite, çev. Mehmet Küçük, Vadi Yayınları, Ankara, 1993: 305).

Düşünür, simülasyon kavramına da modernizm değerlendirmesiyle ulaşmıştır. Baudrillard, çă̆daş kültüre modernizasyon temasıyla bakmaktadır. 1970’lerin başında yazdığı bir makalede moderniteyi, taklit olmayan bir değerlendirme olarak görmüştür. Fakat daha sonra Althusser epistemolojisi etkisinde kalarak modernitenin sahici bir kuram ve yalnızca kuramsal bir sorun olamayacağını yazmıştır. Modernizmi, geniş bir çeşitliliği olan geleneksel kültürden ayıran en önemli özelliğin kültürü bağdaşıklaştırmak (homojenleştirmek) olduğunu savunmuştur.

Bizi düşüncemize göre gerçek bir Batılı olan Baudrillard bir tesbit ve tesbite bağlı olarak bir uyarı yapmaktadır. Onun 'moderniteyi' silmek ya da yok saymak gibi bir düşüncesi yoktur. Çünkü, 
Samsun, M. (2015). Kapitalist bir söylem olarak sanatın sonu. International Journal of Human Sciences, 12(2), 1239-1250. doi:10.14687/ijhs.v12i2.3427

diğer kültürlerin durağanlığına karşın modernite, değişimi ve değişimin değişmezliğini ima etmiştir. Avrupa tarihinde modernizm, bireysel rasyonalizm felsefesi, bilim ve teknoloji ile doğar. Başlangıçta eski ve yeni bir arada çatısmaktadırlar. Bu durum en çok 19. yüzyılda yaşanır. Modernite'nin fenomen bir olgu olarak tanımlanması da bu dönemde gerçekleşmiştir. Bu çatışkı değissimin muharrik gücü olmuştur. Baudrillard'nn bunu reddetmesi mümkün değildir, ancak o bütün bunlara rağmen Batı toplumunun içinde bulunduğu bu belirsizlik durumundan dolayı üzgündür ve bunun yine 'modernite' aracıllğı̆la aşlabileceğini inancındadır. Bu görüşlerimizi destekleyen argümanlara geçmek istiyoruz.

Mike Gane, Baudrillard: Critical and Fatal Theory adlı çalışmasında modernite'nin mantığının geçici bir gelişme doğrultusunda olduğunu söyleyerek şöyle devam eder: "Bu mantık, dünyanın belirli bir hedefe doğru ilerlediğini ve tarihin geri dönülmez birikim olduğunu yansıtmaktadır. $\mathrm{Bu}$ düşüncenin sonucu olarak modernite, bireysel yaratıcllı estetiğini iki önemli sonuca götürmüştür: Avangart ve moda. Her iki sonuç da eski değerleri ve formları ele alarak onları eski bağlamından soyutlamakta ve yeni bir sembol sistemi kurmaktadırlar”. Baudrillard'a göre artık kendiliğinden, içten gelişen devrimler mümkün olamaz. Ama modernitenin devrim düşüncesine karşı olduğu söylenemez. Yine de işin içinde kolayca fark edilemeyen ve geleneksel formlarla oynanan kültürel bir oyun olduğu söylenebilir. Baudrillard düşüncesine göre, bu gün toplum bir simülasyon toplumu haline gelmiştir. "Sessiz. Yiğmlarm Gölgesinde" adlı kitabında simülasyon toplumunu şöyle açıklamaktadır: Toplum denen şey, hem bilinen hem bilinmeyen, her şeyi sünger gibi emen bir yığındır artkk. Bu toplumda politika zavallı bir televizyon şovuna dönüşmüştür. Hayat da bir televizyon şovudur. Baudrillard aynen şöyle demektedir:

Bu yığınlar toplumsala ve politikaya ait iyi bir iletici olmadıkları gibi, daha genel anlamda iyi bir anlam ileticisi de değildir. Devlet, anlam, tarih ve kültür çevresinde oluşturulmuş $1 s ̧ 1 k$ demetlerini emerek ortadan kaldırırlar. Onlar tepkisizliğin, nötr olanın gücüdür (akt. Giderer, 2003: 34-36).

Kapitalizmin toplumu daha iyi sömürmek için ürettiği politikalar sonucu oluşan yığın, şimdi kapitalizmin bile ulaşamadığ bir sessizlik içindedir. Baudrillard’a göre, arttk toplumsal diye bir şeyden söz edilemez. Toplum olarak varsaydığımız şey sessiz yığındır. Bu yığını seçimlerle, kamuoyu yoklamalarıyla, anketlerle ve bilimsel yöntemlerle tanımak ve yönlendirmek olanaksızdır. Yığın kesin bir sessizlik içindedir. Kapitalizmin yığına verdiği tüm rüşvetler, onu konuşturmak için başvurduğu tüm taktikler, dürtüklemeler boşunadır.

Düşünür, bu sessizliğin bilinçli bir tepki olduğunu söylemiştir. Yığınların simülasyon içinde ulaştıkları sonuçtur bu. Artık toplum içindeki kutuplar çökmüştür. Bu nedenle Maksist anlamda bir devrim olasıllğı da ortadan kalkmıştır. Artık ne temsil vardır ne de temsil edilme. Yı̆̆ınların 
Samsun, M. (2015). Kapitalist bir söylem olarak sanatın sonu. International Journal of Human Sciences, 12(2), 1239-1250. doi:10.14687/ijhs.v12i2.3427

yabancılaşması söz konusu değildir, kitlelerin kendi kendilerini olumsuzlamaları düşüncesi bir palavradan ibarettir. Şimdi yığınlar, ne bir olumsuzlama ne de bir patlama alanıdır. Bir emme alanıdır. Dışarıdan verilen her şeyi emer, ama yanıt veremez; çünkü kendi dili yoktur, onun adına konuştuğunu öne sürenlerin söyledikleri de yığınların yanıtı olamaz. Yığın, bir hayvan sürüsü kadar sessizdir.

Baudrillard sanattaki göstergelerin gerçek anlamlarını yitirerek birer simülakra dönüştüğünün en güzel kanıtının hiç şüphesiz “Marlyn” tablosu olduğunu söyler. Çünkü Marlyn Morroe, burada sanatçı kişiliğinden ya da insan özelliğinden çıkarılarak, bir tür tanrıçaya dönüştürülmüştür. Resimdeki farklı renk kullanımları ise sadece seri şekilde üretilen resimlere bir farklılık kazandırmak içindir (Giderer, 1983: 33-36).

Amaçsız, ölçüsüz, iş olsun diye yapılan her şeyin sanat sayıldığı modern dünyada, bir pisuar ya da vesikalık fotoğrafin sanat eseri sayılması ne ölçüde doğrudur? Bu düzeysizliği sorgulayan Baudrillard, bu konuda herkesin bunu sorgulamasını ve sorgulayan kişinin de "gerçek sanatçı" olduğunu savunur. Zaten, “artık resimler bakılmak için değil tüketilmek için yapılır” der Baudrillard.

\section{SONUÇ}

Bir çalışmaya sonuç yazmak, 'sonucun' yeni tartışmaları yok sayacağı anlamına gelmez. Bu nedenle biz vardığımız sonuçların yeni tartışmalar açmasını umut ediyoruz. Vardığımız sonuçlar şöyledir:

1. Çağımız entelleyası içinde 'sanatın sonu'nun geldiği gibi bir düşünce hakimdir. Biz bu düşünceyi hastalıklı ve tarihsel arka plandan yoksun buluyoruz.

2. Modern denilen sanat, Danto'ya göre, tarihini kaybetmiş bir seri yığın üretimi haline gelmiştir. Biz bu görüşü destekliyoruz.

3. Sanatın böylesine içerikten yoksun olmasının tek sebebinin 'kapitalizm' olduğunu düşünmüyoruz. Biz modern düşüncede neden-sonuç bağlamının birbirine karıştırıldığı kanısındayız.

4. Sadece kapitalizm geldi diye sanatın içi boşalmamıştır, sanatın tarihsel arka planından yoksun bir eğitimle ortaya çıkan sanatçılar da bundan sorumludurlar.

5. Baudrillard 'sanatın sonu' söylemiyle başlayan görüşlerinde bir modernizm eleştirisine gitmektedir. Bu modernitenin yok sayılması anlamına gelmez; içinde bulunduğu dekadent durumdan yine 'modernitenin muharrik gücü' ile kurtulacaktır. Böylelikle sanat yine kendi tarihsel arka planına sadık kalarak devam edecektir.

6. Sanatın sonu söylemi her ne kadar olumsuzluk içerse de kendi içinde olumlu bir çekirdeğe de sahiptir. Biz bu söylemlerin biteceği kanısında değiliz. Bu söylemler 
gelecekte de devam edecektir. Ancak bunlar birer çatışkı durumu oluşturarak diyalektik bir süreçle olumlu bir duruma dönüşecektir. Tartışmaların boyutu ne olursa olsun, sanat her zaman, kendi tarihsel arka planını koruyarak varlığını sürdürecektir.

\section{KAYNAKÇA}

Adanır, O., (2004). Baudrillard' in Simülasyon Kuramı Üzerine Notlar ve Söyleşiler, Dokuz. Eylül Yaymlar, İzmir.

Baudrillard, J., (1991). Sessiz Y Yğmlarn Gölgesinde yada Toplumsalın Sonu, Aynntı Yay.,İstanbul.

Baudrillard, J., (1995). "Trans Estetik”, Kötülïğ̈̈̈ Şeffaflŭg: Aşır Fenomenler Üzerine bir Deneme, Çev. Emel Alabora, Işık Ergüden, Ayrınt yay, İstanbul.

Baudrillard, J., (2010). Sanat Komplosu, Çev. Elçin Gen-Işık Ergüden, İletişim Yayınları, İstanbul.

Bumin, T., (1998). Hegel, Yky, Cogito Dizisi, İstanbul.

Copleston, F., (1995) Ffelsefe Taribi: Hegel, Çăgdaş Felsefe, bölüm I. çev Aziz Yardımlı, İdea Yay.

Danto, A.C., ( 2010). Sanatın Sonundan Sonra-Çăgdaş Sanat ve Tarih Sinı Çizgisi, Aynıntı Yayınları, İstanbul.

Duhm, D., (1996). Kapitaližmde Korku, çev. S. Şölçün, Ayraç Yay. Ankara.

Giderer, H. E., (2003). Sanatm Sonu, Ütopya Yayınevi, Ankara.

Kuspit, D., (2006). Sanatm Sonu, Metis Yayınları, İstanbul.

Lynton, N., (1982). Modern Sanatın Öyküsü, çev. Cevat Çapan-Sadi Öziş, Remzi Kitabevi, İstanbul.

Ryan, M., (1993). Postmodern Siyase, Modernite Versus Postmodernite, çev. Mehmet Küçük, Vadi Yayınlar1, Ankara.

Topçuoğlu, N., (2000). Ffotoğraf Ölmedi ama Tuhaf Kokuyor, Yky, İstanbul.

\section{Extended English Abstract}

In the present paper, the claim, art or painting is going through its end, is evaluated as a capitalist discourse; and some related samples were analyzed in terms of how they were passivized and become dysfunctional by the capitalist system. French thinker Jean Baudrillard is the most effective and distinguished sample of the claim, the end of art. In this point, after evaluating Danto's ideas from the modern perspective, the claim of "end of art" will be discussed through Baudrillard's post-modern perspective. When Baudrillard directed his gaze onto the world of art, the situation he saw was not a very optimistic one. Modern art and post-modern art, in which the thinker is also included, is the production of the Western World. As a result, in this sense, the literature of art is merely valid for the modern art taking its roots from the Western World and this domain of thinking. According to Baudrillard, art has lost its own privilege and purpose; it is not made for development of culture, but for consumption of this culture; and instead of existing through its own content of meaning, it has been unconsciously spread over all segments of the society. As a result, the discussion of what is art and what is not has progressively become more ambiguous. This ambiguity has negatively affected the art of the present era. 
The discourse of end of art cannot be perceived as an immediate claim or a slip of the tongue. This is not a new discourse, and there are many factors preparing and supporting this discourse. Additionally, this discourse is consciously prepared, thought over, well-designed and timely. It emerges as an attitude of capitalist social production relations in its efforts to create its own artist. Among other things, postmodernism has also declared the end of political position of art. In the 1980s, the theorists were erecting their ideas on the theme of end of painting. They claimed that the art of painting was heading towards its own consumption and that art and works of art were outside the feelings stemming from the real art as art and works of art were forced away from themselves.

The reason why the art of painting is primarily mentioned while talking about the problem of end of art is its statue among the arts. According to Giderer, destroying the roof of a building means transforming it into a dysfunctional state. When the highest part, which is economically the most productive, the most distinguished, the most demanded, the most appreciated and the most functional one, is demolished, the end of art could easily be brought. As a factual reality, art realizes itself over an object or by an object. This object is capable of being carried, exhibited and bought and sold. This situation does not prove capitalism innocent in terms of the works of arts' capability of being carried, exhibited and bought and sold; capitalism empties art through its movement from the works of art. Warhol has become one of the most distinguished examples criticisms of modern art by constantly reproducing the well-known images of the myths of popular culture, and by emphasizing the problems of the mechanical age, the superficiality of the art produced for anyone and the power of money turning even the most wretched things into precious items.

In conclusion, in capitalism, everything is for sale. Meta is sold in a market of its own. The work of art or the object of art is sold in the market of art. Market is a sovereign hegemony over the artist and art through the galleries, museums, critics. The discourse of end of art has reached its peak though the French thinker Baudrillard.

The Baudrillard's philosophy is based on the idea of simulation. The thinker explains the simulation as follows:

Whereas simulation threatens the difference between the "true" and the "false," the "real" and the "imaginary. If the patient simulates an illness, is he ill? Or not? In this term, simulation is the situation where the patient cannot decide whether he is ill or not. (Baudrillard, 1998:13).

Baudrillard by following Nietzsche wants to express that there is decadence in Simulation. Cause and effect are confused; ideal and teleology are annihilated; a social structure controlled by chaos is reigning. There is no responsibility in the things that are done and this negative situation is always superior. It is really possible to see examples of this in the art of the present era, which is called "modern".

The thinker says that this decadence is a conscious reaction. It is the end result which the mass reaches within the simulation. The poles within the society have collapsed. As a result, the possibility of a revolution in the Marxist sense is extinct. There is no more any representation and being represented. In the modern, where everything lacking ideals, measures are classified as art, to what extend is it possible to classify a pissoir or a mug shot photo as works of art? 